\title{
FAMÍLIA: MATERNIDADE E PROCRIAÇÃO ASSISTIDA
}

\author{
Maria da Graça Reis Braga \\ Maria Cristina Lopes de Almeida Amazonas
}

\begin{abstract}
RESUMO. O presente trabalho trata das transformações que se operam na idéia de família que desenvolvemos no Ocidente. Tais mudanças se devem, entre outros fatores, aos diferentes lugares que a mulher passou a ocupar na família e na sociedade e à constituição de sua identidade pela via da maternidade. Isso também é acompanhado pela decadência do modelo patriarcal, o que gera intensas discussões a respeito de um possível fator de feminilização da cultura e declínio da função paterna. A essas questões somam-se os avanços tecnológicos no campo da medicina da reprodução e as intervenções sobre o corpo feminino, o que tem proporcionado tanto mudanças quanto reforços no modelo de família tradicional ocidental.
\end{abstract}

Palavras-chave: família, maternidade, procriação assistida.

\section{FAMILY: MATERNITY AND ASSISTED REPRODUCTION}

\begin{abstract}
The present article discusses the transformations within the concepts of family in the Western society. These changes are due to (among others reasons) the social position that women have assumed, and to the constitution of a feminine identity based on the fact of becoming a mother. These matters follow the decadence of a patriarchal pattern, which generates discussions regarding a supposed rising of a femininization of culture and the failure of the father role. To these questions recent development of reproductive medicine technologies, and medical interventions upon feminine body can be added, which has provide changes as well as reinforcements to a traditional family model.
\end{abstract}

Key words: Family, maternity, assisted reproduction.

Família, no Ocidente, é um conceito não-estável, que se apresenta de maneiras diferentes em culturas e ethos diversos. Apesar disso, o modelo de família nuclear tem sido privilegiado e tem ocupado um lugar pregnante na idéia que construímos, historicamente, sobre o grupo familiar. Nesse modelo, a mãe passou a ocupar um lugar fundamental, constituindo-se como a identidade principal da mulher, impulsionada por interesses de Estado, que se fizeram presentes, através da entrada em cena de diversos agenciamentos, especialmente a medicina higienista. Vários fatores, como a ascensão profissional da mulher, o divórcio, entre outros, têm contribuído para o declínio do modelo tradicional familiar; no entanto, na contemporaneidade, percebemos um grande movimento de reinvestimento na família.

A conquista de poder, pela mãe, dentro do grupo familiar, aconteceu em paralelo ao declínio do poder do pai, mais precisamente, o declínio do modelo de sociedade patriarcal. As mulheres, então, passaram a transcender o lugar de mães, através de sua entrada no mercado de trabalho e de sua assunção, muitas vezes, do lugar de cabeça da família, como acontece na monoparentalidade. As novas configurações familiares oferecem um novo desafio e uma nova discussão: a questão da subjetivação infantil. Como ficarão as nossas crianças, em meio a tantas transformações? É uma indagação enunciada por muitos.

Uma das maiores peculiaridades contemporâneas da mulher é a possibilidade colocada à sua disposição, pelo desenvolvimento tecnológico, de transformação de seu corpo. Corpos femininos, através da medicina estética; e corpos-fêmea, através da medicina da reprodução. Tais avanços subvertem a posição feminina, mas, ao mesmo tempo, reforçam antigas identidades, como a mulher-objeto ou a mulher-mãe.

As possibilidades oferecidas pelas técnicas de procriação assistida reforçam o estigma da mulher

\footnotetext{
* Psicóloga e mestre em Psicologia Clinica pela Universidade Católica de Pernambuco, Recife.

\# Psicóloga e docente do Mestrado em Psicologia Clínica da Universidade Católica de Pernambuco, Recife, Brasil. Doutora pela Universidade de Deusto, Bilbao, Espanha.
} 
infértil, sob o prisma de que, com todo o avanço tecnológico nessa área, hoje só é infértil quem quer permanecer nesta condição. Os tratamentos para engravidar, no entanto, não são apenas um meio para se atingir um resultado fácil: o filho; mas proporcionam para as pessoas envolvidas vivências e experiências novas, carregadas de afetos contraditórios, muitas dúvidas e ambivalências. Ao mesmo tempo, as novas tecnologias reprodutivas produzem esperança e provocam mal-estar.

\section{FAMÍLIA, CONCEITO E MEMÓRIA}

O que entendemos por família, no Ocidente, é fruto dos diversos agenciamentos culturais (pessoais, sociais, profissionais, de mídia, científicos, entre outros). Dessa maneira, a família é um fenômeno que tem sido compreendido através de vários elementos, como conexões entre consangüinidade e afinidade (sistema de parentesco), um sistema de morada, uma corporatividade, um sistema de atitudes, entre outras características. O sistema de parentesco remete a unidades de parentesco que, por sua vez, remetem à regra de residência, grupo doméstico, grupo de comum pertencimento e formas de regulação das relações interpessoais. Mesmo com algumas semelhanças, são diversas as formas como a família ocidental vem se apresentando através das épocas, dos lugares, das culturas e ethos próprios (Duarte, 1995).

Há quem diga que a família, no sentido em que hoje a percebemos, é fenômeno recente, que a nossa ordenação de família como doméstica e nuclear faz parte de uma grande transformação histórica, não contínua, não linear, não homogênea (Duarte, 1995). Achatar a família no modelo nuclear, como tendo sido central para todas as épocas, empobrece a nossa compreensão de outras formas de organização social (Casey, 1992). Tal redução também cria associações distorcidas em relação aos vínculos familiares, naturalizando-os, como no caso dos vínculos mãe e filho, como se a mulher tivesse sido sempre a mãe burguesa e moderna.

No final do século XVIII, principalmente no século XIX, a mulher aceitou o papel da boa mãe, ainda que isso não tenha se dado de uma forma homogênea. Os novos discursos relativos à maternidade e à família ditaram o perfil dessa mulher, agora mãe dedicada em tempo integral, responsável pelo espaço privado, privilegiadamente representado pela família.

Podemos atribuir o aumento do interesse social pela criança às péssimas condições em que se encontrava o que chamamos hoje de infância, além de outros fatores, como interesses estatais, desenvolvimento de disciplinas, como a medicina e a higiene, a nascente psicanálise, paradigmas que, aos poucos, foram entrando em cena para tentar apagar a indiferença e, muitas vezes, a crueldade da forma de maternidade de certas organizações sociais e familiares anteriores. Começou, então, a era das "provas de amor", como a amamentação, o cuidado, a higiene, a presença materna constante. A dupla identidade característica do feminino - a mulher-mãe - ganhou maior visibilidade e consistência (Badinter, 1980/1985).

O vínculo familiar, através do laço conjugal, passou a não mais servir para, preponderantemente, evidenciar ascendências e garantir linhagens e transmissão patrimonial, mas sim, a servir como modelo aos cuidados sobre a criança, a fim de garantir o indivíduo saudável, adulto. Com essa finalidade, será promovido e valorizado um novo conjunto de instituições que se ocuparão, em auxílio à família, da formação dos sujeitos individualizados: instituições pedagógicas, assistencialistas, higienistas. A nova família é naturalizada e sacralizada, e os defensores da modernidade a concebem como célula-mater natural e inevitável, sinônimo do coletivo de indivíduos.

Fragmentada, reduzida à sua parcela indivisível, a família nuclear, átomo familiar, vai corresponder a um indivíduo coletivo. Tal modelo de família vem se adaptando aos diversos contextos e atualizações da cultura ocidental moderna, porém a maior parte das afirmações comumente referentes à família, na verdade, dizem respeito às camadas médias da população. Nas classes populares, a unidade doméstica não corresponde à família conjugal nuclear, há um grande peso nas redes de apoio da comunidade; e, nas elites, a preocupação com a linhagem, enquanto unidade de identidade, ainda é marcante. De todo modo, o ideal que se constitui como hegemônico, independentemente de camada social, é o modelo de família nuclear.

Sem dúvida, entre os fatores desafiantes desse modelo central de família estão as mudanças que envolveram a questão feminina, a partir da valorização da criança e do papel da mãe, nos séculos XVIII e XIX. Pela ocupação do mercado de trabalho e assunção da família, na ausência masculina, mais intensamente a partir da Primeira Guerra Mundial, a mulher assumiu o projeto individualizante da modernidade. Porém, pelo menos uma das tarefas partilhadas pelo grupo familiar ficou resistente à individualização completa: a procriação. Isso, de fato, providenciou um "agenciamento simbólico universal muito específico para a produção das identidades 
contrastivas do masculino e do feminino" (Duarte, 1995, p.37).

Assim, um modelo importante de família ocidental, com base na soberania paterna e ratificado pelos modelos sagrados da tradição cristã, foi desafiado pelo feminino, a partir do século XVIII, transformando-se com a burguesia e enfatizando a maternidade. O movimento de afirmação da mulher e da criança, assim como o declínio do pai, gerou e gera angústia e desordem, pelo terror, mais propriamente contemporâneo, da ameaça do fim do pai, da abolição da diferença sexual, reduzida à mínima diferença, e da dissolução do modelo familiar tradicional, numa sociedade que passou a cultuar, não mais o grupo familiar, mas sim, cada um dos seus membros.

A família burguesa, dominante no apogeu da modernidade, engendradora dos sujeitos modernos, a partir dos movimentos liberais e de questionamentos, que apontavam para conquistas igualitárias e libertárias, passou a ser contestada, ainda mais, a partir do século XX, e rejeitada, acusada de ser uma instância colonizadora, repressora, sócia do capitalismo burguês e maior obstáculo ao prazer e à liberação dos corpos femininos e infantis. Fato recente, que vem intrigando os estudiosos sobre família, é que as pessoas excluídas pelo modelo tradicional de família (nuclear, conjugal, heterossexual), principalmente os homossexuais, têm procurado adotar a ordem familiar que sempre os rejeitou: assiste-se a um "desejo de família" (Roudinesco, 2003).

\section{RUMORES SOBRE A AMEAÇA DO DECLÍNIO DO PAI}

Hoje, provavelmente, o que incomoda é a adesão ao modelo familiar por parte das antigas ameaças à família, como os homossexuais, feministas, prostitutas, libertinos, inférteis e malthusianos ${ }^{1}$. O temor, mais uma vez, é de que a família seja desvirtuada de seus valores tradicionais, da lei do pai e da autoridade, e entre em decadência, a partir das novas configurações familiares. É o temor do fim do pai e da ascensão da mãe.

\footnotetext{
Genericamente o termo define casais que optam por não ter filhos e, na contemporaneidade, reflete a situação do casal em que ambos trabalham, têm uma dupla renda no orçamento familiar, todavia não desejam filhos - double income, no kids. Mas a origem do termo se refere à doutrina do economista inglês, Malthus, no século XVIII, que preconizava um nível ideal de população e de renda per capita, restringindo o aumento populacional.
}

Tal temor, de certa forma, vem sendo corroborado pelas novas tecnologias de procriação, que permitem à mulher dispor ou não dispor do homem para procriar, sobretudo a clonagem reprodutiva, que vem ameaçar séculos de supremacia do sêmen. Para o Mundo Ocidental, parece ser pior a dispensabilidade do homem do que o tempo remoto, perdido na história da humanidade, em que era desconhecida a participação masculina na procriação.

Para Ceccarelli (2002), uma expressão como "declínio do poder paterno" requer uma maior reflexão, pois se trata de declínio do patriarcado, e não do pai propriamente dito. O que está ameaçado é a referência ao pai como única possibilidade de subjetivação, questionamento sobre o caráter imaginário de uma forma de organização social onde o homem ocupa o centro. O pai como função de ser "o outro da mãe" e o fato de que esta função tenha de ser desempenhada pelo homem é que estão mudando. Para o autor, a crise da masculinidade é realmente a crise dos homens, cada vez menos convocados a ocupar esse lugar.

Tornar-se pai é correr o risco de pressentir que o filho assinalará a sua morte, que será seu sucessor e que superará a sua herança. Isso pressupõe que o pai reconheça a transitoriedade do lugar que ocupa, pois este foi ocupado anteriormente por outro, e que o seu filho, assim como ele, também o ocupará transitoriamente.

Roudinesco (2003) pontua que o pai não perdeu toda a sua autoridade, mas sim, o excedente de poder, o direito excessivo de vida e morte sobre a mulher e os filhos, sendo hoje a autoridade compartilhada. A autora também não acredita no perigo da feminização da sociedade, pois, mesmo tendo o poder sobre a procriação, as mulheres o exercem pela mediação dos homens (e também dos médicos), além dos direitos conquistados e reivindicados pelos filhos. Perigo, talvez, seja o fato de a criança vir a ocupar o lugar de objeto, no sentido de coisa, e também de uma ordem mundial em que só exista uma única potência, detentora das tecnologias e patentes referentes à criação e manipulação do ser humano, ou seja, um mundo como um vetor com direção única.

$\mathrm{O}$ Ocidente tem apresentado mudanças significativas de valores, comportamentos e identidades, e mudanças nas formas de filiação. $O$ longo processo da modernidade, caracterizado pela intervenção e emancipação humanas em seu mundo, intensifica-se com a revolução industrial e com os processos deflagrados a partir dela e das grandes guerras mundiais. O lugar do homem e da mulher nas 
relações sociais tem estado em foco, desde então. Temas como separação entre sexualidade e procriação (antes: sexo sem procriação, ultimamente: procriação sem sexo), avanços tecnológicos, aumento da longevidade, movimentos feministas, revolução sexual, divórcio, consumo, entre outros, articulam-se no tecido social, de forma a alterar sensivelmente a nossa forma de vida, na atualidade.

\section{SUBJETIVAÇÃO INFANTIL}

O terror do fim do casamento e da família não é recente, tanto se falou a respeito dos filhos de casais separados como se fala a respeito dos filhos de casais homossexuais. Bem ou mal, as famílias continuam se compondo e recompondo, as crianças continuam se subjetivando, pois o modelo tradicional de família não se pode colocar como ideal, posto que sempre produziu o mal-estar e o adoecimento, ao lado dos seus melhores exemplos aceitáveis socialmente. Isso pode nos alertar para o fato de que não existe "uma maneira, um caminho, que defina, de forma única e definitiva, e muito menos normativa, o acesso à Ordem Simbólica e às relações entre sujeitos próprias do humano" (Ceccarelli, 2002: p. 90). Não se pode tomar uma posição ortopédica nos estudos sobre o assunto, de uma autoridade legitimada pelo saber que venha nos dizer como a dinâmica da filiação deve ocorrer.

$\mathrm{Na}$ constituição de um sujeito, acreditamos que o mais importante é que ele seja simbolicamente reconhecido, seja pelos pais, seja pela família, seja pela comunidade. O essencial é que a família possa ser esse lugar de reconhecimento e suporte para o desamparo da criança. É isto que transforma a criança de um corpo em um ser falante, desejante, um sujeito em uma cultura, enredado em uma teia cultural que aponta para um "antes" e um "depois" dele. Importante no processo de subjetivação infantil é poder atravessar um momento inicial de completude para uma etapa seguinte de investimento nos outros, no mundo ao seu redor.

As diferentes formas de filiação, como nos casos da homoparentalidade e da monoparentalidade, manifestam suas dificuldades em se sustentar num modelo familiar que tenta não as considerar. Porém, algo fundamental é uma construção de maternidade e paternidade em relação à organização psíquica daqueles que cuidam da criança, como eles se colocam diante de sua própria sexualidade, da relação com sua família de origem, diante do imaginário que cada um tem de ser mãe e de ser pai, e, principalmente, o lugar que a criança ocupa para os pais.
Temível pode ser uma situação em que a criança seja transformada em objeto de consumo, prazer ou fetiche, criada sem cuidado e sem afeto. As famílias são sempre construídas, e os filhos, sempre adotivos. O que define família são os investimentos afetivos, com as suas vertentes de ternura, de erotismo e também de agressividade. Devemos estar atentos a toda idealização de família e de filiação, pois apenas o tempo poderá nos dizer mais sobre o assunto (Ceccarelli, 2002).

\section{FEMINILIDADE E MATERNIDADE}

Para a mulher, uma problemática atual importante gira em torno do corpo, seja para as adolescentes seja para as adultas, supostamente com identidades formadas, que fazem deslizar tal problemática das questões estéticas para as questões que se referem à procriação. Os limites e delineações do corpo adquirem a possibilidade de transcendência. Para quem tem vontade, disciplina (e dinheiro), pelo menos existe a pretensão de não ter mais o que suportar ou buscar elaborar na relação com o próprio corpo, basta transformar.

O saber médico e as investigações científicas e tecnológicas são movidos também por esse sintoma. As intervenções sobre o corpo ultrapassam as paredes dos consultórios e ganham o espaço do senso comum e da mídia. O corpo que ganha terreno na atualidade não é o corpo imaginário da psicanálise, mas o corpo em carne, que pode ser recortado e recosturado, tocado, violado, atravessado, virado ao avesso, entregue a um discurso científico e a uma definição biológica. Um corpo que pode trazer a possibilidade de felicidade se for retirado e transformado o que, nele, aciona a angústia na mulher (Breyton \& Armênio, 2001).

Quinet (2002) nos fala a respeito da medicina e da tecnologia, atualmente, como, mais que nunca, um produto da combinação entre ciência e discurso capitalista, através da medicalização crescente da saúde e da formatação de novas demandas endereçadas aos médicos. Um mercado que se revela como mais-valia, que obedece a um apetite cego e sem limites, sem ter o que o impeça; a oferta de uma tentação, sob a forma de possibilidade de escolha, grande demais para que se possa resistir.

As novas tecnologias reprodutivas são uma realidade que se oferece ao consumidor, numa relação onde os resultados veiculados pela propaganda, muitas vezes ilusórios e imprecisos, têm seu espaço garantido. Não é claro, transparente e linear o caminho que vai do desejo pelo filho ao nascimento de uma 
criança; no entanto, são essas lacunas que a mitologia científica tenta e é chamada a preencher. Tecnologias de procriação se associam à investigação e à terapia genética, associação não muito distante de um ideal eugênico. Nossa ancestralidade e tradição, atualmente, têm sido expressas através do nosso genoma (Quinet, 2002).

Historicamente (principalmente a partir do século XVIII), a maternidade tem sido construída como o ideal máximo da mulher, caminho da plenitude e realização da feminilidade, associada a um sentido de renúncia e sacrifícios prazerosos. A maternidade alcançou um lugar de sofrimento voluntário e indispensável à constituição da mulher, tanto da que não tem como da que tem dificuldade para engravidar. A dor do parto equivale à dor do tratamento contínuo de uma infertilidade resistente.

Em uma pesquisa sobre o imaginário social das mulheres, no que se refere à infertilidade (Trindade $\&$ Enumo, 2002), constatou-se, em diversas faixas etárias e estratos sociais, que a maternidade é idealizada e entendida como um salto qualitativo para a vida da mulher. Apesar das mudanças de concepção em relação à infertilidade, inclusive em virtude do desenvolvimento tecnológico, que veio atender os inférteis e propiciar resultados antes impossíveis, a condição de infértil ainda pesa emocionalmente para a mulher e permanece como fator estigmatizante.

As autoras nos falam a respeito de três modelos psicológicos de infertilidade. $\mathrm{O}$ primeiro modelo, psicogênico, colocava a infertilidade em uma dimensão psicossomática, considerando os mecanismos e conflitos em relação ao papel materno, identidade sexual feminina, imaturidade e histeria, dividindo mulheres inférteis e férteis e, dentre as primeiras, as que tinham causas orgânicas e as que não poderiam ser explicadas.

Com o avanço das técnicas sobre a infertilidade, entra em cena o segundo modelo, que considera os conflitos emocionais como conseqüência, e não causa do problema, a infertilidade como sendo uma das principais crises da vida. Esse modelo, porém, permanece enfatizando a questão das diferenças e semelhanças emocionais entre os férteis e os inférteis.

Já o terceiro modelo se constitui sobre os estudos acerca do estresse, descrevendo e analisando os indicadores que facilitariam ou dificultariam o ajustamento à situação. $\mathrm{O}$ quadro atual mostra aspectos psicológicos múltiplos, abrangendo os pessoais como estresse, sentimentos de perda e comprometimento de auto-estima - e também as dificuldades para o relacionamento conjugal e social. Passou-se a considerar o significado da maternidade e paternidade como também indicadores na questão da infertilidade.

A literatura corrente sobre infertilidade (Abdelmassih, 1999; Abdelmassih, 2001; Highlights in fertility and sterility, revista eletrônica da American Society for Reproductive Medicine - ASRM; Sociedade Brasileira de Reprodução Assistida - SBRA) geralmente é de natureza médica e procura discutir as questões da infertilidade em termos de causas orgânicas e técnicas indicadas. Ainda precisamos que sejam desenvolvidas mais pesquisas sobre o problema da infertilidade e da procriação, sob o prisma da psicologia clínica, da antropologia, da sociologia, por exemplo, para que possamos compreender acerca do que é vivido, do que se sente, do que se imagina, das repercussões socioculturais, enfim, da influência desses fenômenos nos processos de subjetivação contemporâneos.

Tratamentos médicos para engravidar provocam um desgaste físico e psíquico enorme, uma alquimia de angústia, esperança, tensão, frustração, aliada a conceitos e preconceitos culturais, preocupações com as questões econômicas, pressões sociais e familiares. O homem e a mulher são invadidos em seu íntimo, de todas as formas, além de que experienciam ressentimentos e culpabilização mútuos, sem falar no período de tratamento, assim como da infertilidade, que interfere em seu relacionamento conjugal e nos seus projetos de vida, os quais ficam reduzidos a um único: o filho.

A experiência da maternidade, desde o começo, é uma espécie de experiência de desrazão temporária, provocando na mulher afetos de teor heróico, de estado de graça, de ambivalência, de angústia. Diante da possibilidade de serem mães, muitas mulheres se sentem atravessando uma ponte precária, que desabará quando terminar a travessia e impedirá a volta. Essa possibilidade traz um sentimento de estar diante das portas do paraíso e diante de um abismo, de um excesso de responsabilidade (pela vida do outro), de pânico, de poder, a sensação boa e, ao mesmo tempo, não tão boa, de que nunca mais poderá estar sozinha (Aragão, 2002).

A gravidez, no dizer de Winnicott (1956/2000) especialmente nos últimos meses - e as primeiras semanas de nascimento do bebê configuram-se como um período especial, no qual a mulher se prepara para um estado diferente, quase uma doença, de desenvolvimento de uma sensibilidade exacerbada, o que lhe possibilitará identificar-se com o seu bebê, de maneira a deixar os seus outros interesses e investimentos, ao menos temporariamente. Paradoxalmente, a mulher precisa ser saudável o 
suficiente para sair desse estado, quando for liberada pelo bebê (e compreender que está sendo liberada).

Tornar-se mãe é um reencontro com a própria experiência como filha de sua própria mãe. É tornar o vazio (angústia e desconhecimento) familiar, é estabelecer um vínculo permanente com o estrangeiro. Este estrangeiro (mesmo quando desejado), de invasor, passa a ocupar um lugar e um espaço para a mulher, através de uma série de movimentos, de aproximações; ou seja, o bebê passa a tomar corpo na barriga e no psiquismo da mãe. $\mathrm{O}$ desejo por um filho e a gestação constituem um estado muito "fértil" para a produção do imaginário feminino e para um "tornar a ver" nas suas posições infantis (Aragão, 2002).

Culturalmente, o feminino se encarnou na maternidade. Certamente, a gravidez não resolve o problema de identidade da mulher, posto que ela também se sente mulher quando não está grávida; porém a clínica com mulheres que apresentam dificuldades para engravidar revela que muitas delas têm necessidade de ter um filho para se sentirem mais seguras e mais mulheres, em vez de excluídas e vazias. Uma mulher grávida se dá a ver, parece que passa a existir. A gravidez dá visibilidade ao feminino, que tem sido representado (e a psicanálise tem muito a ver com isso) como falta de algo fundamental e como fonte de mistério. A mulher que afirma desejar um filho constrói uma demanda, elabora um pedido, mesmo que não seja manifestamente a alguém endereçado. Nos casos de fertilização artificial, entretanto, essa demanda é dirigida ao médico e imediatamente aceita, sem reflexões.

\section{INFERTILIDADE E PROCRIAÇÃO ASSISTIDA}

A clínica psicanalítica fornece algumas possibilidades de compreensão acerca da vivência de um tratamento para infertilidade. Uma mulher que se submeteu à fertilização in vitro, em atendimento psicanalítico (Campos, 2002), revela-nos a dificuldade moral que sente, ao ser tocada em seu corpo, em partes muito íntimas, que, inclusive revelam o seu segredo e sua incapacidade de dar a si mesma uma criança. Ter instrumentos o tempo todo dentro de si, provoca medo nas relações sexuais, em virtude de uma expectativa de dor, mesmo sabendo que, antes do tratamento, a relação era prazerosa.

A mulher quer ter um filho (não necessariamente ser mãe), e, por isso, busca e se submete ao tratamento, mas é um querer também carregado de dúvida e de ressentimento, posto que remete ao relacionamento com sua própria mãe. Duas mulheres, em que uma, a mulher-mãe, vai conceder simbolicamente, ou não, a capacidade de fertilidade à mulher-filha, para que esta também se torne mãe. A mulher-mãe é capaz, como mulher, de dar a vida a alguém. $\mathrm{O}$ dom que uma mãe, imaginariamente, pode ceder à filha é uma possibilidade de identificação com essa mulher ideal, longe do alcance, que lhe autoriza ser também mulher.

Cordeiro, Carvalho, Cunha e Lins (2002) nos falam a respeito da importância da dívida (em relação àqueles que contribuem para a nossa formação), na constituição dos sujeitos, relacionando fecundidade e filiação feminina. Todos nós temos necessidade de dívida, já que a nossa vida nos é dada não gratuitamente, sendo necessário transmitir o que nos foi dado, mantendo o circuito da dívida simbólica, transmissão esta também referente a outros processos criativos, além da procriação.

Um filho dado pela tecnologia, aparentemente, corrige as falhas e retoma a cadeia, mas também reafirma uma condição de fracasso. Esse fracasso pode apontar para outras maneiras de se alcançar a feminilidade que não a identificação com a própria mãe e com a maternidade: separação, elaboração de um luto materno e assunção de sua própria singularidade, deixando-se livre para desejar (inclusive o desejo por um filho) ou buscando para isso identificações com mulheres terceiras. Essa última também pode ser uma maneira de se pagar uma dívida e conquistar e construir uma feminilidade própria.

As novas tecnologias reprodutivas fornecem um campo privilegiado em possíveis articulações entre o feminino e o desejo de ter um filho. As mulheres com dificuldade para engravidar são confrontadas com esse desejo, são obrigadas a parar para pensar nele. Quando a mulher pede uma criança, todos acreditam que exista um desejo, mas muitas vezes a necessidade de uma criança provém da pressão da sociedade, onde a mulher é caracterizada pela sua capacidade de procriar (Campos, 2002).

$\mathrm{O}$ desejo por uma criança se sustenta no senso comum pelo pressuposto social de que é natural da mulher, e isso legitima socialmente a demanda, tornandoa incontestável. Tudo se deve fazer, então, para atendê-la. Com certeza, a gravidez não é a única via de realização da feminilidade, porém o fato de que só a mulher pode engravidar (pelo menos por enquanto) assinala a maternidade como traço absoluto que distingue não apenas os sexos, mas também os gêneros.

Os procedimentos de reprodução assistida, apesar de estarem sempre definidos sob o título de novas tecnologias reprodutivas - NTR (mesmo tendo o primeiro bebê de proveta nascido há quase três décadas) são a continuidade de um processo moderno de intervenção e 
instrumentalização crescente do homem sobre o mundo e sobre si mesmo, e de um processo contínuo de medicalização e controle dos corpos, da sexualidade e da reprodução (Corrêa, 2000).

O caráter de novidade de tais procedimentos é sempre atualizado pela presença da mídia explorando o assunto, pelas suas associações com outras tecnologias, como a genética, pelo debate ético ainda precário e pelas repercussões nas concepções de família, filiação, subjetividade e identidade. O caráter de novidade, pelo menos no Brasil, também se afirma através da falta de registros completos das atividades laboratoriais e das clínicas de reprodução, assim como pelas lacunas ainda não preenchidas pela legislação, o que compromete a regulamentação, vigilância e fiscalização por parte das agências coletivas.

Se a tecnologia vem responder a uma antiga demanda, o desejo de ter filhos, desejo de família, as respostas, ficam no campo de uma medicina pósmoderna, ou seja, disponibilização de técnicas, no mesmo modelo de medicamentos revolucionários como o prozac e o viagra, modelo de falta e preenchimento da falta, defeito e correção imediata e temporária, política de resultados. Provavelmente essas novas tecnologias também estão ocupando um lugar na demanda atual por filhos e também, possivelmente, criam um "novo desejo do desejo de filhos" (Corrêa, 2000, p. 865).

A utilização de células reprodutivas doadas por terceiros sempre foi instigante nesse campo. A princípio, a ênfase recaiu na doação de sêmen e na demanda por produções independentes. Hoje, a doação de óvulos assume um lugar de destaque no processo. Parece haver um consenso, e os especialistas apontam isso: que a doação de óvulos é mais fácil, menos sofrida para o casal, do que a doação de sêmen. Isso pode acontecer por se poupar ao homem a freqüente insuportabilidade de conviver com a situação de sua mulher gestar um filho que é dela e de um outro homem. A mulher que gera em seu útero um filho geneticamente de seu marido com outra mulher tem na gestação e no parto (dizem os especialistas) a prova visível de que o filho é seu. Em nome da alegria e da realização do sonho de um casal, ao constatar a gravidez e com o nascimento do bebê, pouco se discute, se sabe, se pesquisa ou se estuda em relação ao que acontece com homens e mulheres durante o processo e depois, ou seja, para o resto da vida.

A infertilidade ocorre em todas as classes sociais, porém, muitas vezes, por motivos diferentes. Ressaltando a importância aqui da não-generalização, o que ocorre é que as mulheres das classes populares muitas vezes têm sua infertilidade determinada também por razões de prevenção possível, como abortos, infecções maltratadas, a que se somam as mulheres esterilizadas (Corrêa, 2000). As mulheres de classes média e alta, muitas vezes, têm sua infertilidade determinada também pela idade e pelo adiamento da maternidade em função da carreira e da ascensão profissional, além de outras demandas que vêm se somar ao desejo por um filho relacionadas à possibilidade de escolha de características desejadas para o futuro bebê, como o sexo, cor dos olhos, da pele, cabelos, até mesmo características intelectuais, gostos e preferências, mesmo que se saiba que essas últimas podem não passar pelos genes.

Em um estudo sobre a maternidade como produção independente, (Szapiro \& Féres-Carneiro, 2002) nos chamam a atenção para o fato de que a experiência de maternidade apelidada, pós os anos 1960 de "produção independente", pode ser vista como uma preliminar das novas tecnologias de procriação. Isso é possível, pois alguns elementos de seu discurso anunciam também um imaginário que concede legitimidade às novas tecnologias de procriação, especificamente a separação entre sexualidade e procriação, legitimidade que foi impulsionada a partir dos contraceptivos e do controle, pela mulher, da procriação, aliada ao discurso individualista liberal.

O movimento feminista colocou a maternidade, que restou enquanto diferença irredutível entre masculino e feminino, no seio de amplos debates a respeito da posição social de homens e mulheres e conseqüente construção de uma ordem igualitária, intensificada na segunda metade do século XX. A maternidade alcançou o status de escolha autônoma, através do "empurrãozinho" dado pela ciência. "A crença na liberdade de escolha como valor, como formadora da idéia de indivíduo é o indicador de verdade do imaginário moderno... Toda restrição colocada pelo outro social é repudiada em nome da liberdade de escolha" (Szapiro \& Féres-Carneiro, 2002, p. 181).

A produção independente, como tentativa de construir um novo lugar para a mulher, erigiu uma contradição, pois realizou o seu intento através do traço identificatório mais tradicional do feminino na cultura: a maternidade. Interessante perceber que, com as tecnologias de procriação, homens e mulheres permanecem iguais, porém ambos submetidos ao especialista e à técnica.

\section{CONSIDERAÇÕES FINAIS}

Com o privilégio dado ao plano biológico nas questões referentes à filiação, estamos nos esquecendo, paulatinamente, de que é somente a 
transmissão de um patrimônio simbólico que permite as novas gerações se situarem num sistema de filiação, encontrando um lugar no grupo ancestral de referência, caminho possível para a construção de um sujeito da ética.

A respeito desta reflexão, acreditamos que as discussões que se desdobram no campo do tema das novas tecnologias de procriação devem continuar permanentemente vivas e em aberto, pois a velocidade dos procedimentos queima etapas preciosíssimas para os sujeitos envolvidos, mais especificamente para a mulher. Um tempo, que não se mede cronologicamente, é necessário para que se permita o sentir, o pensar, o elaborar. São procedimentos que envolvem muitas perdas, muitos questionamentos e muitas reflexões.

$\mathrm{O}$ feminino não se traduz na maternidade, o desejo pelo filho não é inelutável ou imprescindível. A maternidade se configura nessa fronteira complexa entre natureza e cultura, entre força impulsionadora e construção permanente. Ao contrário do que apregoa a nova ideologia do "vale tudo para realizar um sonho", talvez valha a pena, sim, sonhar, experimentar a nossa possibilidade de virtualidade; e não adquirir, por preços altíssimos em todos os sentidos, sonhos prontos e empacotados nas sofisticadas vitrines registradas e amparadas pelo rótulo de científicas.

Limites e bordas nos rondam todo o tempo, na verdade nos dão forma e consistência, e não podemos prescindir deles, sob o risco de vivermos sem atribuir sentido aos fenômenos de nossa vida. A família do presente e do futuro é, e deve ser, permanentemente reconstruída a partir do passado que repercute no presente, considerando o que nela pode ser considerado como muito importante: suporte para o desamparo, horizonte ancestral e geracional, idéia de enredamento.

\section{REFERÊNCIAS}

Abdelmassih, R. (1999, $2^{\mathrm{a}}$ ed.). Tudo por um bebê.. São Paulo: Globo.

Abdelmassih, R. (2001). Aspectos gerais da reprodução assistida. Em Bioética. Revista Conselho Federal de Medicina, 9(2), 15-24.

Aragão, R. O. (2002). De mães e de filhos. Disponível em: <http://www.estadosgerais.org> (Acessado em 22/02/2002).

Badinter, E. (1985). Um amor conquistado: o mito do amor materno.(W. Dutra, Trad.). Rio de Janeiro: Nova Fronteira. (Trabalho original publicado em 1980).
Breyton, D. \& Armênio, E. (2001). O corpo, campo de batalha contemporâneo. Disponível em: 〈http://www.estadosgerais.org> (Acessado em 05/09/2002).

Campos, D. (2002). Mãe e filha: da identificação à devastação. Disponível em: <http://www.estadosgerais.org> (Acessado em 16/12/2002).

Casey, J. (1992). A história da família. São Paulo: Ática.

Ceccarelli, P. R. (2002). Configurações edípicas da contemporaneidade: reflexões sobre as novas formas de filiação. Pulsional Revista de Psicanálise, 15(161), 88-98.

Cordeiro, A. B. Z., Carvalho, A. Y. C., Cunha, M. C. V., \& Lins, M. T. I. A. C. (2002). Da depressão ao desejo de pró-criar: revisitando a feminilidade na clínica e na transmissão da psicanálise. Disponível em: <http://www.estadosgerais.org> (Acessado em 05/09/2002).

Corrêa, M. V. (2000). Novas tecnologias reprodutivas: doação de óvulos. O que pode ser novo nesse campo? Cadernos de Saúde Pública, 16(3), 863-870.

Duarte, L. F. D. (1995). Horizontes do indivíduo e da ética no crepúsculo da família. Em I. Ribeiro \& A. C. T. Ribeiro (Orgs.) Família em processos contemporâneos: inovações culturais na sociedade brasileira (pp. 27-41). São Paulo: Loyola.

Highlights in fertility and sterility (2002). Revista eletrônica da ASRM - American Society for Reproductive Medicine. Disponível em: <http://www.asrm.org> (Acessado em março 2002).

Quinet, A. (2002). As novas formas do sintoma na medicina. (Artigo on-line) Disponível em: 〈http://www.estadosgerais.org> (Acessado em 05/09/2002).

Roudinesco, E. (2003). A família em desordem. Rio de Janeiro: Zahar.

SBRA - Sociedade Brasileira de Reprodução Assistida. (2002). Disponível em <http://sbra.com.br> (Acessado em abril de 2002).

Szapiro, A. M. \& Féres-Carneiro, T. (2002). Construções do feminino pós anos sessenta: o caso da maternidade como produção independente. Psicologia: Reflexão e Crítica, 15(1), 179-188.

Trindade, Z. A. \& Enumo, S. R. F. (2002). Triste e incompleta: uma visão feminina da mulher infértil. Psicologia USP, 13(2), 151-182.

Winnicott, D. W. (2000). A preocupação materna primária. Em Da pediatria à psicanálise (pp.399-405). Rio de Janeiro: Imago, (Originalmente publicado em 1956).

Recebido em 25/07/2004 Aceito em 04/11/2004

Endereço para correspondência: Maria Cristina Lopes de Almeida Amazonas. Rua do Futuro, 77, apto 1201, Graças, Recife-PE. E-mail: crisamaz@elogica.com.br. 